\title{
Impact of Weekdays on the Return Rate of Stock Price Index: Evidence from the Stock Exchange of Thailand
}

\author{
Pichit Boonkrong*, Nithipa Arjrith \\ Email address: \\ pichit.bk@rsu.ac.th(P. Boonkrong),nithipa@rsu.ac.th(N. Arjrith) \\ ${ }^{*}$ Corresponding author
}

Department of Mathematics, College of Information and Communication Technology, Rangsit University, Pathum Thani, Thailand

To cite this article:

Pichit Boonkrong, Nithipa Arjrith. Impact of Weekdays on the Return Rate of Stock Price Index: Evidence from the Stock Exchange of Thailand. Journal of Finance and Accounting. Vol. 6, No. 1, 2018, pp. 35-41. doi: 10.11648/j.jfa.20180601.15

Received: February 18, 2018; Accepted: April 17, 2018; Published: April 27, 2018

\begin{abstract}
This research aims to study the effect of the days in week on the return of the stock price index, particularly in the Stock Exchange of Thailand (SET). The daily closing prices of SET50 index from June 2, 2003 to June 2, 2017 are taken into account, i.e., there are totally 3,425 days. The stock returns of the 50 companies are calculated according to the daily historical stock prices of companies. Both descriptive and inferential statistics are employed in data analysis including average, standard deviation, multiple comparisons and multiple regression analysis. Applying ordinary least square method, the linear equation with five dummy variables is formulated for multiple regression analysis. The results show that the means of daily return rate of SET50 index are significantly different. Monday has a negative influence on the return rate of SET50 index whereas Friday has a positive influence at the significance level of 0.05 . The return rate of SET50 index on Monday is lowest whilst Friday is highest during the week.
\end{abstract}

Keywords: Least Square Method, Market Anomalies, Multiple Regression, SET50 Index, Stock Price Index

\section{Introduction}

The advances in multidisciplinary science at presence have globally resulted in a longer lifespan of human beings. By the fact that Thailand is in the transitional period into elderly society, making financial planning after retirement becomes more and more important. Money reserved for daily expenses, medical fee or other expenses in the future may come from pension funds, savings, interest rates, bank deposits, business investment or other dividends. Nevertheless, investing in any business may need a large budget and have the risk of loss. Recently, it is seen that interest on bank deposits or dividends tends to be less or zero. For these reasons, we should look for some channels to increase revenue without much investment but a better return than bank deposit. One of the good channels is to invest in the stock market.

The Stock Exchange of Thailand (SET) was established by the Stock Exchange of Thailand Act 1974 under the supervision of the Office of the Securities and Exchange Commission (SEC). Officially, the Stock Exchange of Thailand has firstly traded on 30 April 1975 and many companies have started registering with. SET has acted as intermediaries to exchange equity securities of the registered companies. To mobilize more capital from the public easily, SET allows anyone to join the investment and to be one of the shareholders of the company. To accommodate the issuing of index futures and options in the future, and to provide a benchmark of investment in the SET, the SET50 and the SET100 indices were launched taking into account the top 50 and 100 listed companies on SET in terms of large market capitalization, high liquidity and compliance with requirements regarding the distribution of shares to minor shareholders [11]. The lists of SET50 and SET100 indices are reviewed every six months in order to adjust for any changes. Investing in the stock market, investors will benefit from dividends or profit from the difference of securities price. If the investors buy the stocks at a low price, then the stock price gets higher, investors will be profitable. In contrast, if investors buy stocks at high price, then the stock price gets lower, investors will lose. Of course, all investors want only 
profit. However, securities prices are always changing in correspondence with many factors, e.g., company operations, world economy and political situations. Investors must study how the stock price has changed, how return rate becomes more or less, and clarify whether it is worth to invest. If investors know enough about this information, it will help reduce the risk of investment. Considering the day of the week, investors may come up with the simple questions, e.g., when the suitable time to trade should be and how much impact of the day-of-the-week anomalies affects the return rate.

Reviewing the relevant literatures, many papers have studied the return rate or changing direction of securities price. It was found that days of the week influenced the yield of the stock price index [1-9]. For instance, Gibbons (1981) conducted a study of the influence of weekday in the US stock market between November 1974 and December 1979. It was found that the return on Monday was the lowest. Aly et. al (2004) investigated daily stock market anomalies in the Egyptian stock and capital market in a four-day trading week. Their results showed that Monday returns are significantly positive, but are not different from the rest of the week. Marrette and Worthington (2008) considered the day-of-the-week effect in Australian daily stock returns and found that there was evidence of a small cap day-of-the-week effect with systematically higher returns on Thursdays and Fridays. Agathee (2008) studied the effect of the day on the return of the Mauritian Exchange Index in 2006. It found that Friday had a higher return than any other day. Marrette, Liu and Li (2010) studied day-of-the-week effects in the top 50 Australian companies across different industry sectors. The largest mean weekday returns occurred on Monday for 15 companies and the returns on Monday were significantly larger than the rest four days for six companies. Haroon and Shah (2013) observed day-of-the-week effect in Karachi Stock Exchange (KSE) of Pakistan using different five models of ordinary least square regression to investigate each day-of-the-week effect. They suggested that investors are able to gain more benefit by investment or withdrawal on Monday and Friday. Cengiz et al. (2017) investigated the day of the week effects on stock index of Turkey. It was found that the effect on Monday was negative, Tuesday had the least effect, but Thursday and Friday had the highest effect on the stock return. Zhang, Lai and Lin (2017) employed the method of rolling sample test and the Generalized Autoregressive Conditional Heteroskedasticity (GARCH) model to investigate the day-of-the-week anomalies in stock returns in 28 main stock markets in 25 countries over the world. Each weekday had significant impact on different stock markets.

Based on the aforementioned researches, it is questioned whether the return in stock market of Thailand has the same effect from weekday and which weekday dramatically affects the return rate of SET50 index. The research methodology including descriptive and inferential statistics is illustrated in
Section 2 and its empirical results are presented in Section 3. The distributions of daily return rates of SET50 index from five different weekdays are graphically presented. The means of return rate from five different weekdays are compared against each other. The linear equation with five dummy variables is formulated corresponding with the effect of each weekday. The value of the regression coefficient indicating the daily effect from each weekday is figured out by multiple regression. Finally, some conclusion and discussion are also given in Section 4.

\section{Research Methodology}

\subsection{Data Source}

Since there are hundreds of companies registering in the list and it is quite difficult to do research on stock prices of all companies, this research mainly focuses on the return rate of SET50 index. The Stock Exchange of Thailand has set the benchmark SET50 index to promote the issuance of derivatives and be a market indicator for mutual funds. SET50 index is a share price index showing the level and movement of the top 50 market capitalization shares. To investigate the effect of weekday on SET50 index, daily closing price of SET50 index from June 2, 2003 to June 2, 2017 are appointed as the population in this research, i.e., there are 3,425 days with daily closing prices as shown in Figure 1.

\subsection{Study Selection}

Concerning data analysis, the presentation is divided into two main parts including descriptive and inferential statistics using Microsoft Excel and SPSS as software tools. Descriptive statistics presents the average and standard deviations of the SET50 index return rate classified by days of the week. For inferential statistics, the mean values of return rate of SET50 index from five weekdays are compared through hypothesis testing with ANOVA F-test. Additionally, an ordinary least square (OLS) method is performed. Initially, eeach daily closing price of SET50 index is transformed to be daily logarithmic return in order to lessen influence of extreme arithmetic returns using the formula:

$$
R_{t}=\ln \left(\frac{P_{t}}{P_{t-1}}\right)
$$

where $R_{t}$ denotes the return rate at time $t$ (days), $P_{t}$ and $\mathrm{P}_{\mathrm{t}-1}$ denote the closing prices at time $\mathrm{t}$ and $\mathrm{t}-1[5,9]$. The plot of return rate of SET50 index is displayed in Figure 2. Subsequently, the descriptive statistics including mean, standard deviation, minimum and maximum can be obtained as presented in Table 2 . 


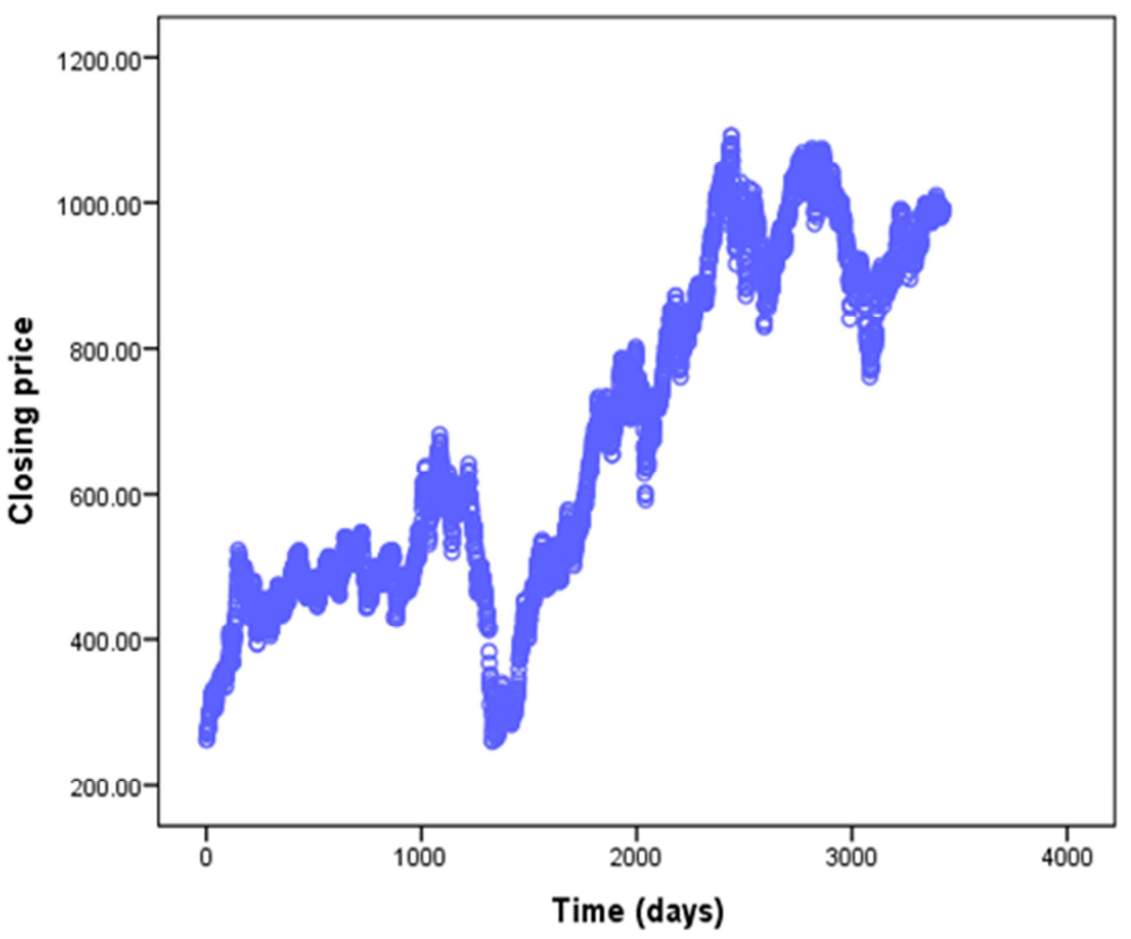

Figure 1. Closing price of SET50 index.

\subsection{Statistical Model}

A multiple regression is employed to find out if the average return rate of SET50 index differs amongst five weekdays: Monday, Tuesday, Wednesday, Thursday and Friday $[2,3,6,8]$. To compare the mean values of the stock returns from each weekday, analysis of variance techniques can be applied. Particularly in econometrics, a dummy variable takes the value 0 or 1 to indicate the absence or presence of some categorical effect. In this study, days of the week are expected to shift the return rate of SET50 index; thus, days of the week are considered as dummy variables and their effect on stock market return is examined. Next, the linear equation with five dummy variables starting from the origin is formulated as follow:

$$
\begin{aligned}
\mathrm{R}_{\mathrm{t}} & =\beta_{1} \mathrm{D}_{1 \mathrm{t}}+\beta_{2} \mathrm{D}_{2 \mathrm{t}}+\beta_{3} \mathrm{D}_{3 \mathrm{t}}+\beta_{4} \mathrm{D}_{4 \mathrm{t}}+\beta_{5} \mathrm{D}_{5 \mathrm{t}}+\boldsymbol{\varepsilon}_{\mathrm{t}} \\
& =\sum_{\mathrm{i}=1}^{5} \beta_{\mathrm{i}} \mathrm{D}_{\mathrm{it}}+\boldsymbol{\varepsilon}_{\mathrm{t}}
\end{aligned}
$$

where $R_{t}$ and $\varepsilon_{t} \sim \mathrm{N}\left(0, \sigma^{2}\right)$ denote the return rate and its error at time $t$ (day). The parameters $\beta_{1}, \beta_{2}, \beta_{3}, \beta_{4}$ and $\beta_{5}$ denote the coefficients for Monday, Tuesday, Wednesday, Thursday and Friday, respectively. Five dummy independent variables $\mathrm{D}_{1 \mathrm{t}}, \mathrm{D}_{2 \mathrm{t}}, \mathrm{D}_{3 \mathrm{t}}, \mathrm{D}_{4 \mathrm{t}}$ and $\mathrm{D}_{5 \mathrm{t}}$ are accordingly defined for Monday, Tuesday, Wednesday, Thursday and Friday, respectively. To be clarified in Table $1, D_{1 t}=1$ if $t$ is Monday and $D_{1 t}=0$ if $t$ is another weekday. Likewise, the dummy variables $D_{2 t}, D_{3 t}, D_{4 t}$ and $D_{5 t}$ are also defined in the same manner. A dummy independent variable $D_{i t}, i=1,2,3,4,5$ for some observation having the value of 0 reflects that variable's coefficient has no role in influencing the dependent variable $R_{t}$. On the other hand, the dummy variable taking the value of 1 shows its role on the dependent variable $R_{t}$. To be more obvious, the main goal of this paper is to figure out the values of all considered coefficients $\beta_{\mathrm{i}}$ for $\mathrm{i}=1,2,3,4,5$ through multiple regression analysis in model (2). Then, the values of all considered coefficients will indicate how much they affect the return rate from the SET50 index.

Table 1. Value codes of dummy variables used in model (2).

\begin{tabular}{llllll}
\hline Weekday & $\mathbf{D}_{\mathbf{1 t}}$ & $\mathbf{D}_{\mathbf{2 t}}$ & $\mathbf{D}_{\mathbf{3 t}}$ & $\mathbf{D}_{\mathbf{4 t}}$ & $\mathbf{D}_{\mathbf{5 t}}$ \\
\hline Monday & 1 & 0 & 0 & 0 & 0 \\
Tuesday & 0 & 1 & 0 & 0 & 0 \\
Wednesday & 0 & 0 & 1 & 0 & 0 \\
Thursday & 0 & 0 & 0 & 1 & 0 \\
Friday & 0 & 0 & 0 & 0 & 1 \\
\hline
\end{tabular}

\section{Empirical Results}

Gathering information of SET50 index, Microsoft Excel and SPSS are employed in the process of data analysis. The data assessment begins with the transformation of all closing price into the return rate. As displayed in Figure 2, all closing prices are converted into the return rates using the formula in equation (1) and then are presented by the scatter plot. It is seen that the return rates are not so different. The distributions of daily return rate of SET50 index are presented by histograms in Figure 3 (a) - (e) and their normal Q-Q plots are presented in Figure 4 (a) - (e). Graphically, it is seen that the daily return rates slightly depart from the straight line; however, they are acceptably considered as normal distribution in this study. Descriptive statistics of 
SET50 index return rate classified into weekday is presented in Table 2. It indicates that the daily return of the SET50 index on Monday is the lowest and negative whilst the daily return of Friday is the highest during the week. In addition, the daily standard deviations from 3,425 days are nearly the same.

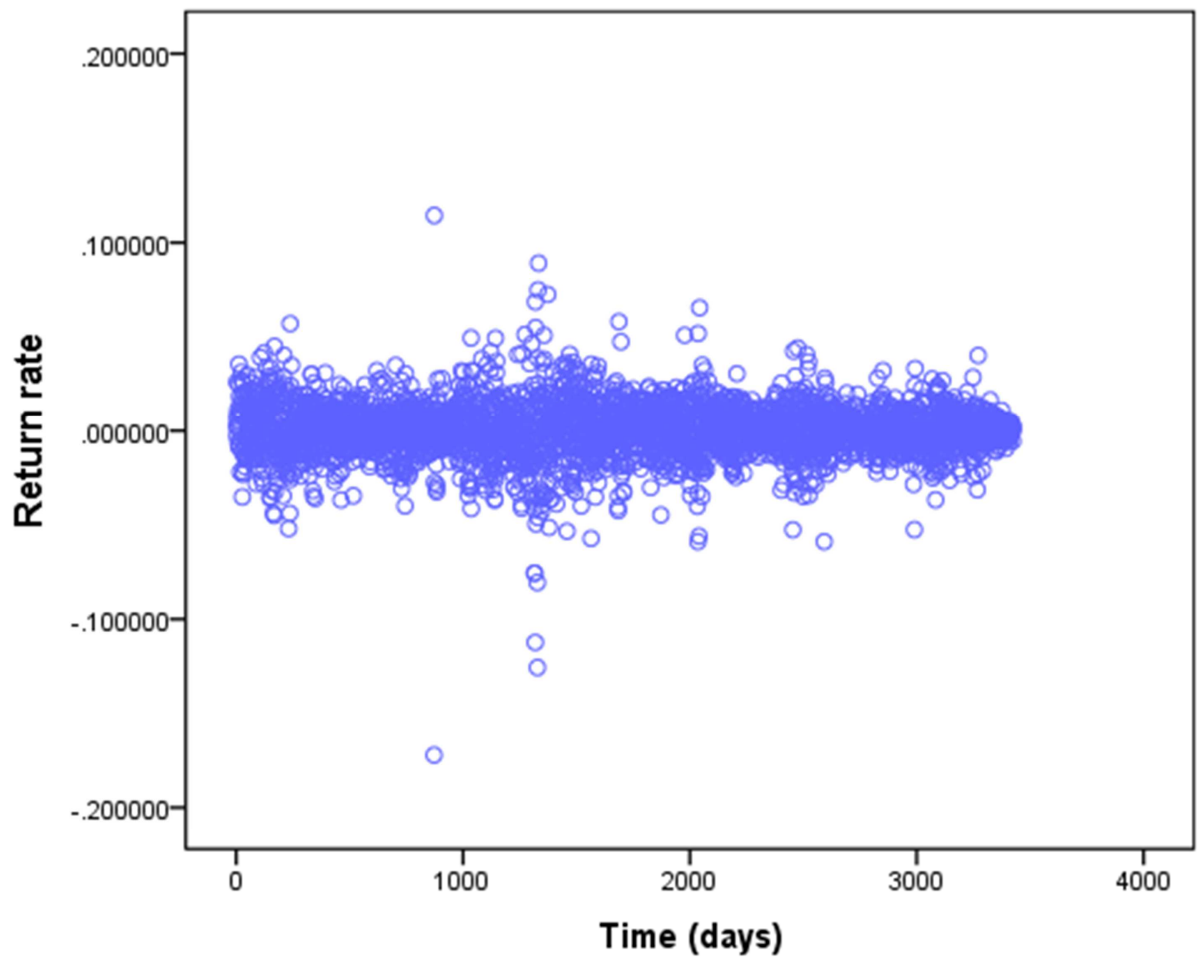

Figure 2. Return rate of SET50 index.

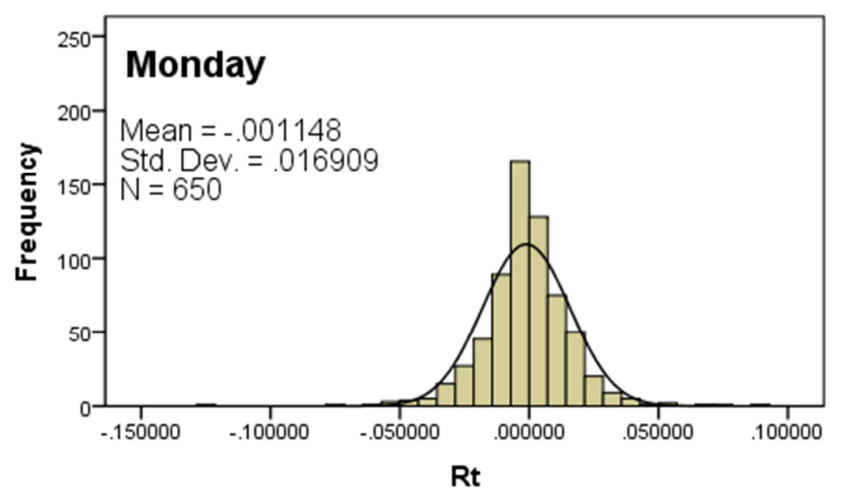

(a)

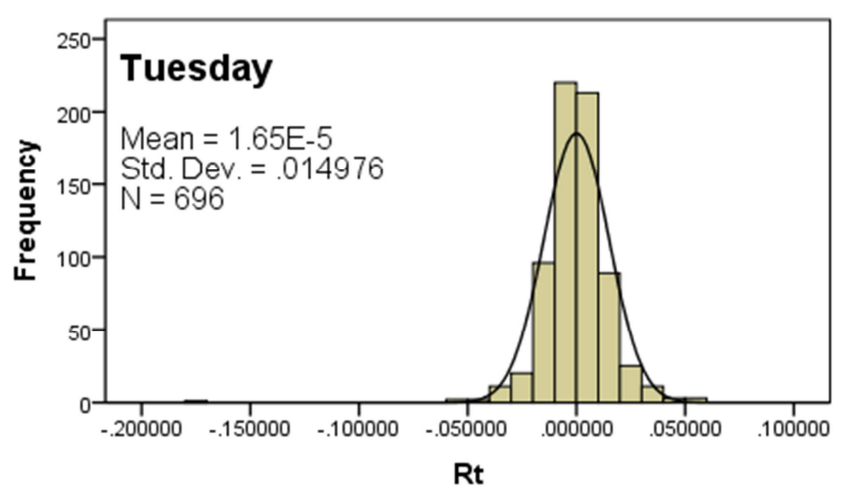

(b)

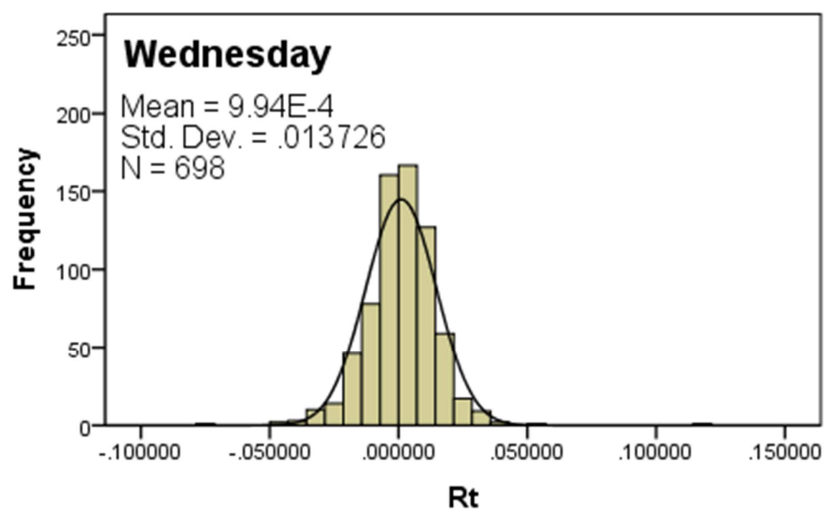

(c)

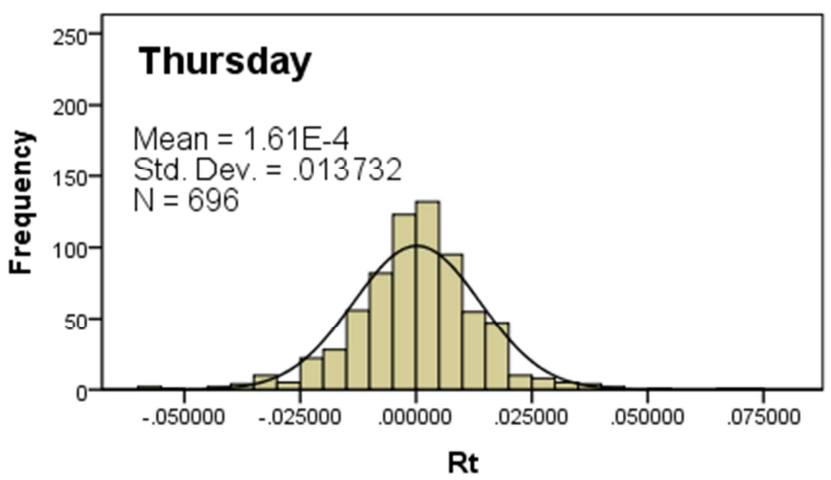

(d) 


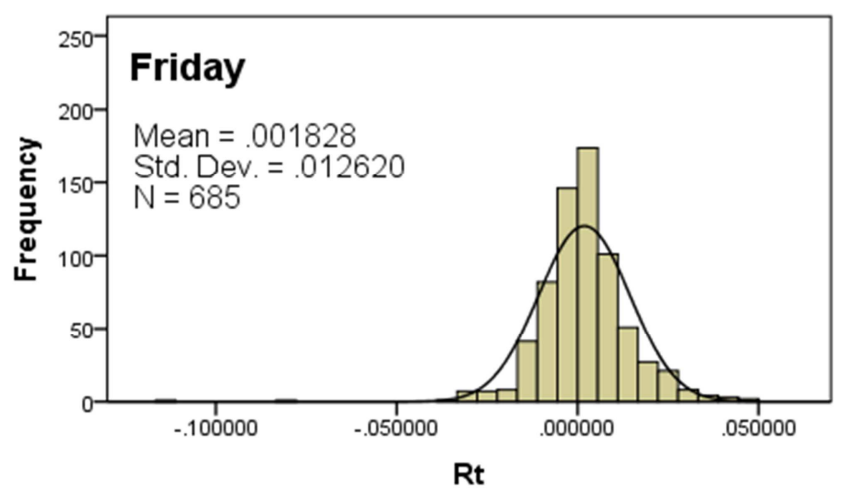

(e)

Figure 3. Histograms graphs fit with normal distribution of daily return rate of SET50 index from five different weekdays.

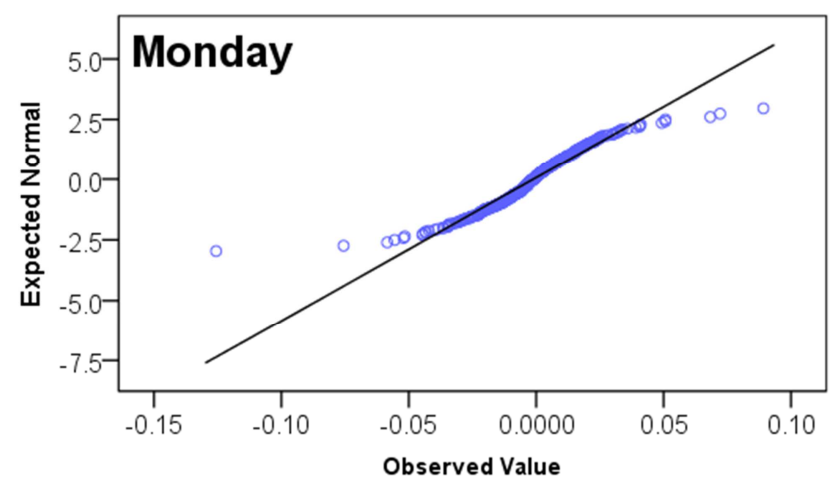

(a)

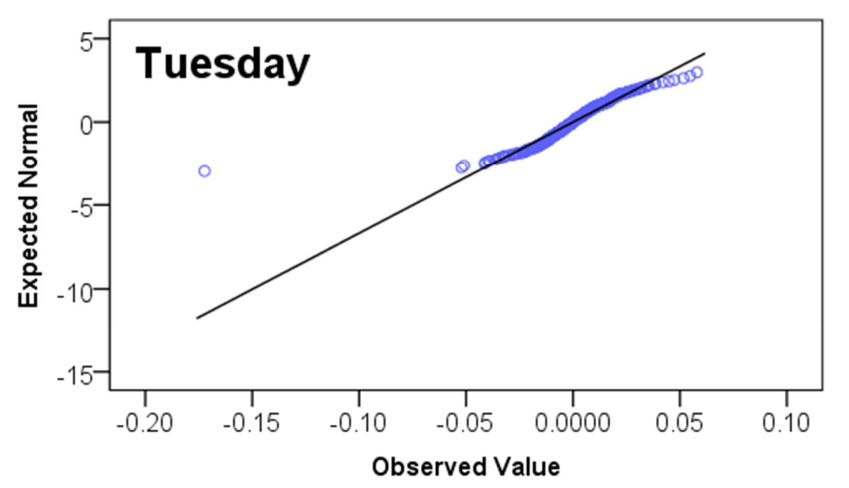

(b)

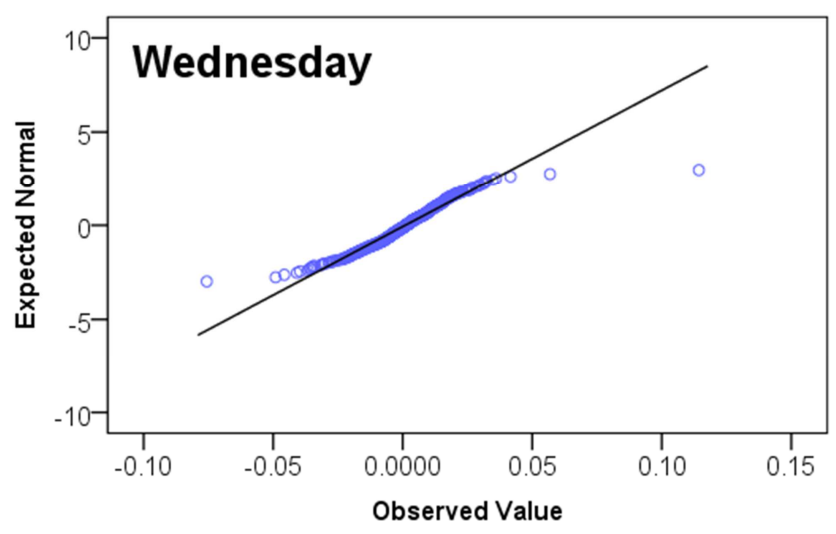

(c)

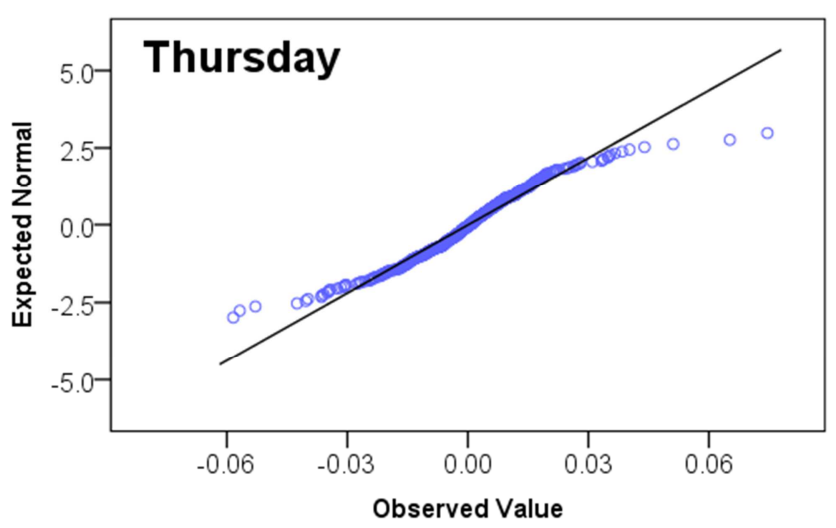

(d)

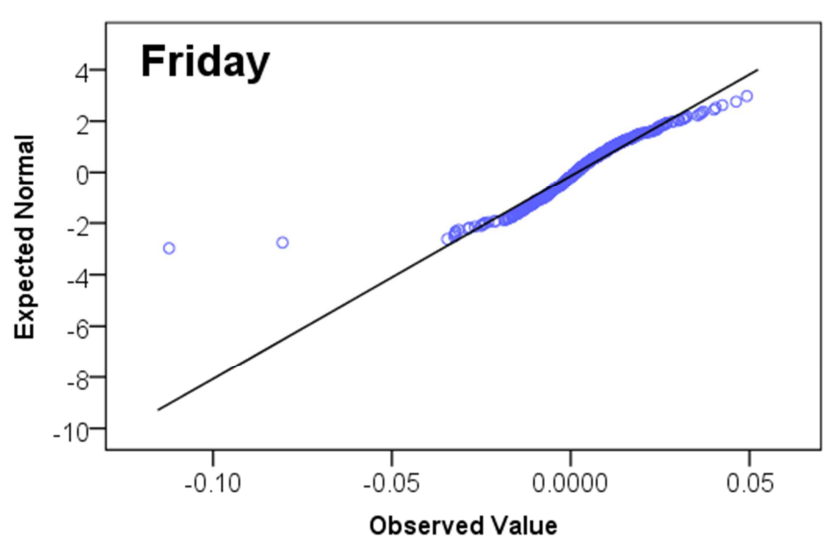

(e)

Figure 4. Normal Q-Q plots with normal distribution of daily return rate of SET50 index from five different weekdays.

Table 2. Descriptive statistics of SET50 index return rate.

\begin{tabular}{llllll}
\hline Weekday & $\mathbf{n}$ & Mean & Std. Dev & Min & Max \\
\hline Monday & 650 & -.00114798 & .016909052 & -0.125635 & 0.089165 \\
Tuesday & 696 & .00001650 & .014975860 & -0.172309 & 0.057921 \\
Wednesday & 698 & .00099396 & .013726375 & -0.075629 & 0.114312 \\
Thursday & 696 & .00016100 & .013731547 & -0.058396 & 0.074570 \\
Friday & 685 & .00182827 & .012620480 & -0.112297 & 0.049241 \\
\hline
\end{tabular}

Next step, it is essential to test whether the mean of return rates from each day are different. The multiple comparison test is employed for such hypothesis. Let $\mu_{1}$, $\mu_{2}, \mu_{3}, \mu_{4}$ and $\mu_{5}$ denote the means of return rates on Monday, Tuesday, Wednesday, Thursday and Friday, respectively. The means of five sample sets are compared; in other words, we are going to examine the following hypothesis:

$$
\begin{aligned}
& \mathrm{H}_{0}: \mu_{1}=\mu_{2}=\mu_{3}=\mu_{4}=\mu_{5} \\
& \mathrm{H}_{\mathrm{a}}: \mu_{\mathrm{i}} \neq \mu_{\mathrm{j}} \text { for } \mathrm{i}, \mathrm{j}=1,2,3,4,5 \text { and } \mathrm{i} \neq \mathrm{j} .
\end{aligned}
$$

At the significance level of 0.05 , the means of return rates from five weekdays are compared against each other using the ANOVA F-test and multiple comparison test as shown in Table 3 and 4. 
Table 3. ANOVA F-test from five sample sets.

\begin{tabular}{llllll}
\hline & Sum of Squares & df & Mean Square & F & Sig. \\
\hline Between Groups & .003 & 4 & .001 & 4.010 & .003 \\
Within Groups & .713 & 3420 & .000 & & \\
Total & .716 & 3424 & & & \\
\hline
\end{tabular}

As $\mathrm{F}=4.010$ and Sig. $=0.003<0.05$, the null hypothesis $\mathrm{H}_{0}$ is rejected, i.e., $\mathrm{H}_{1}$ is accepted. It can be claimed that the means of five sample sets are significantly different. Regarding Table 4, the return rates between Monday and Wednesday, Monday and Friday, Tuesday and Friday, and Thursday and Friday are significantly different. Otherwise, they are indifferent. Considering the effect of weekday on the SET50 index return rate using multiple regression as in equation (2), it is necessary to test whether the daily effect has an impact on the stock return. Analogously, the values of the regression coefficients $\beta_{\mathrm{i}}$ is being examined by the following hypothesis:

$$
\begin{aligned}
& H_{0}: \beta_{i}=0 \text { for } i=1,2,3,4,5 . \\
& H_{a}: \beta_{i} \neq 0 \text { for } i=1,2,3,4,5 .
\end{aligned}
$$

The null hypothesis indicates that $\mathrm{D}_{\text {it }}$ has no influence on the return rate $R_{t}$ whereas alternative hypothesis presents the effect of $D_{i t}$. Next, it is essential to know how much effect of each weekday on the return rate. Thus, multiple regression analysis is employed to figure out all $\beta_{\mathrm{i}}$. Processing data using SPSS as shown in Table 5, the null hypothesis $\mathrm{H}_{0}$ is rejected for $\beta_{1}$ and $\beta_{5}$. Thus, the alternative hypothesis $H_{a}$ is accepted and $\beta_{1}, \beta_{5} \neq 0$. In words, it yields that only Monday and Friday have the significant impact on such the SET50 index return rate. To be more specific, Monday has a negative influence, but Friday has a positive influence to the SET50 index return rate.

\begin{tabular}{|c|c|c|c|c|c|c|}
\hline \multirow{2}{*}{ (i) Day } & \multirow{2}{*}{ (j) Day } & \multirow{2}{*}{ Mean Difference (i-j) } & \multirow{2}{*}{ Std. Error } & \multirow{2}{*}{ Sig. } & \multicolumn{2}{|c|}{ 95\% Confidence Interval } \\
\hline & & & & & Lower Bound & Upper Bound \\
\hline \multirow{4}{*}{ Monday } & Tuesday & -.001164478 & .000787437 & .139 & -.00270837 & .00937942 \\
\hline & Wednesday & $-.002141938^{*}$ & .000786892 & .007 & -.00368476 & -.00059911 \\
\hline & Thursday & -.001308976 & .000787437 & .097 & -.00285287 & .00023492 \\
\hline & Friday & $-.002976251 *$ & .000790484 & .000 & -.00452612 & -.00142638 \\
\hline \multirow{4}{*}{ Tuesday } & Monday & .001164478 & .000787437 & .139 & -.00037942 & .00270837 \\
\hline & Wednesday & -.000977460 & .000773310 & .206 & -.00249366 & .00053874 \\
\hline & Thursday & -.000144498 & .000773865 & .852 & -.00166178 & .00137279 \\
\hline & Friday & $-.001811773 *$ & .000776965 & .020 & -.00333514 & -.00028841 \\
\hline \multirow{4}{*}{ Wednesday } & Monday & $.002141938^{*}$ & .000786892 & .007 & .00059911 & .00368476 \\
\hline & Tuesday & .000977460 & .000773310 & .206 & -.00053874 & .00249366 \\
\hline & Thursday & .000832962 & .000773310 & .281 & -.00068323 & .00234916 \\
\hline & Friday & -.000834313 & .000776413 & .283 & -.00235659 & .00068797 \\
\hline \multirow{4}{*}{ Thursday } & Monday & .001308976 & .000787437 & .097 & -.00023492 & .00285287 \\
\hline & Tuesday & .000144498 & .000773865 & .852 & -.00137279 & .00166178 \\
\hline & Wednesday & -.000832962 & .000773310 & .281 & -.00234916 & .00068323 \\
\hline & Friday & $-.001667275^{*}$ & .000776965 & .032 & -.00319064 & -.00014391 \\
\hline \multirow{4}{*}{ Friday } & Monday & $.002976251^{*}$ & .000790484 & .000 & .00142638 & .00452612 \\
\hline & Tuesday & $.001811773^{*}$ & .000776965 & .020 & .00028841 & .00333514 \\
\hline & Wednesday & .000834313 & .000776413 & .283 & -.00068797 & .00235659 \\
\hline & Thursday & $.001667275^{*}$ & .000776965 & .032 & .00014391 & .00319064 \\
\hline
\end{tabular}

Table 4. Multiple comparison of return rates of SET50 index from five weekdays.

* The mean difference is significant at the 0.05 level.

Dependent Variable: Return Rates

Tukey HSD

Table 5. Test results of daily influence to the daily return rate of SET50 index.

\begin{tabular}{lll}
\hline Weekday & Coefficients & Sig. \\
\hline Monday & -0.042 & $0.018^{*}$ \\
Tuesday & -0.016 & 0.402 \\
Wednesday & 0.025 & 0.176 \\
Thursday & -0.010 & 0.607 \\
Friday & 0.040 & $0.024^{*}$ \\
\hline
\end{tabular}

$* \operatorname{Sig}<0.05$.

\section{Discussion and Conclusion}

This paper has illustrated an idea to study the influence of weekdays on SET50 index return rate for making decision in stock investment. The time series of SET50 index return rate is analyzed using descriptive and inferential statistics. Testing hypothesis, the means of five daily return rate are significantly different. Employing ordinary least square 
method to study the daily influence on the return rate, we obtain that Monday has a negative influence, but Friday has a positive influence to the SET50 index return rate. That is, Monday has the lowest, but Friday has the highest return rate among other weekdays. Using least square analysis, the linear equation with five dummy variables has informed the nature of stock market. On Monday, the return rate of the SET50 index has dropped the most and this result is in correspondence with the papers written by Gibbons (1981) and Cengiz et al. (2017). Because Monday is the first trading day of the week, some investors have not decided to trade or they may gradually sell the securities purchased before the weekend to retain profits. They are not confident in the trend of stock prices that will change in any direction. For other reasons, the fall in return rate on Monday may be due to some critical events, news and stock prices of foreign securities opened during weekend. Unlike Monday, Friday has a positive influence to the SET50 index return rate because investors are confident to trade securities after all relevant information during five weekdays has been analyzed. It is noted that our result coincides with the research paper proposed by Agathee (2008), Marrette and Worthington (2008) and Cengiz et al. (2017). Based on the results from this research, trading securities in SET50 index on Monday and Friday is significant for a higher return. However, investors need to keep in mind that the daily return rate of SET50 index is not very different. There are not only days of the week, but also many factors that must be incorporated into the investment plan.

\section{Acknowledgements}

The authors would like to gratefully acknowledge the Research Institute of Rangsit University for the financial support and thank the Stock Exchange of Thailand (SET) for the data used in this paper. Furthermore, we would like to express gratitude to the anonymous referees for providing valuable suggestions to complete the manuscript.

\section{References}

[1] Agathree, U. S. Day of the Week Effects: Evidence from the Stock Exchange of Mauritius (SEM), International Research Journal of Finance and Economics, 2008, 17, pp. 7-14.

[2] Aly, H., Mehdian, S. and Perry, M., An Analysis of Day-of-the-Week Effects in the Egyptian Stock Market, International Journal of Business, 2004, 9 (3), pp. 301-308.

[3] Bollerslev, T., Generalized Autoregressive Conditional Heteroskedasticity, Journal of Econometrics, 1986, 31, pp. 307-327.

[4] Cengiz, H., Bilen, Ö., Büyüklü, A. H. et al., Journal of Global Entrepreneurship Research, 2017, 7:4. DOI 10.1186/s40497-017-0062-6.

[5] Gibbons, M. and P. Hess., Day of the Week Effects and Asset Returns, Journal of Business, 1981, 54, pp. 579-596.

[6] Gujarati, D. and Porter, D., Basic Econometrics. Singapore: McGraw-Hill Companies. Inc., 2009.

[7] Haroon, M. and Shah, N., Investigating Day-of-the-Week Effect in Stock Returns: Evidence from Karachi Stock Exchange Pakistan, Pakistan Journal of Commerce and Social Science, 2013, 7 (2), pp. 381-393.

[8] Liu, B. and Li, B., Day-of-the-Week Effects: Another Evidence from Top 50 Australian Stocks, European Journal of Economics, Finance and Administrative Sciences, 2010, 24, pp. 78-87.

[9] Marrett, G. and Worthington, A., The Day-of-the-Week Effect in the Australian Stock Market: An Empirical Note on the Market, Industry and Small Cap Effects, International Journal of Business and Management January, 2008, pp. 3-8.

[10] Zhang J., Lai YZ. and Lin JH. The Day-of-the-Week Effects of Stock Markets in Different Countries, Finance Research Letters, 2017, 20, pp. 47-62.

[11] The Stock Exchange of Thailand (2017), SET Index Series, Retrieved from https://www.set.or.th/th/products/index/setindex_p3.html. 